\title{
TONANTZIN: VICTOR TURNER, WALTER BENJAMIN E ANTROPOLOGIA DA EXPERIÊNCIA*
}

Citações são como salteadores, diz Walter Benjamin (I993a: 6I), "que irrompem armados e roubam ao passeante a convicção". No ensaio de Victor Turner "Hidalgo: a história enquanto drama social" (I974d: I05; 2008d: 98), há uma citação deste tipo - do historiador Robert Ricard (I966: I9I):

O culto de Nossa Senhora de Guadalupe e a peregrinação a Tepeyac - a colina perto da Cidade do México onde se diz que a "Virgem Morena" de Guadalupe apareceu pela primeira vez ao índio asteca e catecúmeno Juan Diego, cerca de dez anos após a Conquisa espanhola, e que, incidentalmente, é a colina na qual a deusa pré-hispânica Tonantzin fora adorada antes da chegada de Cortez - parecem [...] ter nascido, crescido e triunfado com o apoio do espiscopado, em face da [...] turbulenta hostilidade dos frades menores do México. ${ }^{\mathrm{I}}$

Como uma lontra que lampeja dos fundos de um texto, aparece Tonantzin nessa citação. ${ }^{2}$ Num quase esquecimento, "incidentalmente", no adendo de uma frase entre travessões. Surge e desaparece. Depois retorna por um instante quase ao final do artigo.

No referido ensaio, Turner retoma uma questão discutida por historiadores da Insurreição de Hidalgo, de I8ıo: por que o carismático líder revolucionário, no dia do "grito de Dolores", empunhou a bandeira de Nossa Senhora de Guadalupe? E somos surpreendidos por Tonantzin. Como um detalhe - provocando uma sensação de punctum, como diria Roland Barthes (1984: 46-47) - ela quase aparece. E se afunda. É ela que "parte da cena, como 
uma flecha, e vem me transpassar". Como um elemento do acaso, da natureza do imprevisível. Presença de uma ausência. Algo ali me fere ou mortifica: um detalhe me punge. Olhamos para Nossa Senhora, de onde emerge o sentido das coisas, e somos movidos pela imagem irrequieta de Tonantzin.

Apesar da novidade nesse livro de uma análise de Turner sobre um processo revolucionário, estamos - mesmo em I974 - em terreno familiar. ${ }^{3}$ As categorias e as formas de interpretação acionadas na primeira parte do texto já eram conhecidas. A Insurreição leva as marcas de uma sequência de dramas sociais. Trata-se de um momento liminar, em meio ao qual surgem símbolos poderosos, tais como a Nossa Senhora de Guadalupe, capazes de suscitar experiências de communitas e de unificar um corpo social dilacerado por profundos conflitos e tensões oriundos da história da Conquis ta e do período colonial. A própria história ganha as feições de um rito de passagem.

Após a descrição detalhada da Insurreição de Hidalgo enquanto forma dramática, o ensaio de Turner ameaça desmanchar-se. Interrompendo o fluxo da interpretação, o texto se revela como um canteiro de obras. Como quem busca formas alternativas para discutir questões estruturais levando em conta os seus aspectos movediços e conflituosos, o autor introduz e experimenta com as noções de "campo", "arena" e "jogo". No registro da subjuntividade, Turner apresenta um excurso conceitual sem o detalhamento da pesquisa etnográfica: "Por isso, se meu objetivo fosse o de fazer um estudo antropológico sério do processo completo da Insurreição de Hidalgo... (Turner, I974d: ı36; 2008d: I26, tradução minha)". ${ }^{4}$ No final, um despertar. A discussão sobre relações entre passado e presente ganha densidade. Retorna a imagem de Nossa Senhora de Guadalupe. E de Tonantzin, energizando o texto.

Nesse ensaio pretendo explorar os efeitos de um pequeno assalto, conforme descrito no início: a aparição de Tonantzin numa citação de Turner. E seu retorno no final do texto. Creio que Turner não apenas produz um deslocamento do lugar olhado das coisas, nos levando a compreender o levante de Hidalgo a partir de um dos símbolos mais poderosos da experiência mexicana - a imagem de Nossa Senhora de Guadalupe -, mas, assim fazendo, ele também provoca um segundo deslocamento: de Nossa Senhora a Tonantzin.

As reflexões que ocorrem no final do ensaio marcam uma inflexão na antropologia de Turner. No ensaio sobre Hidalgo, elas surgem como indícios de uma antropologia emergente. Em fins dos anos 1970, inspirado pela discussão de Richard Schechner (I98I) sobre "comportamento restaurado", Turner tematiza relações entre passado e presente, e elabora uma "antropologia da experiência". Como parte dessa discussão ele também propõe uma antropologia da performance. Em I982, um ano antes de sua morte, Turner publica From ritual to theatre: the human seriousness of play. E organiza a coletânea 
Celebration: studies in festivity and ritual. Postumamente, são publicados, em I985, On the edge of the bush: anthropology as experience; em I986, "Dewey, Dilthey and drama: an essay in the anthropology of experience"; e, em I987, The anthropology of performance.

Creio que esses escritos do "velho" (ou novo) Turner iluminam aspectos importantes do ensaio sobre Hidalgo. Mas, esse ensaio também pode nos fazer repensar algumas das formulações posteriores. Ao nos situar em algumas das margens interiores da antropologia da experiência e da performance, encontramos afinidades entre Victor Turner e Walter Benjamin. Creio que uma crítica imanente dessa antropologia, em companhia de Benjamin, poderá revelar a força de alguns dos elementos mais surpreendentes do pensamento de Turner. ${ }^{5}$

A proposta de explorar as afinidades entre Benjamin e Turner talvez cause estranheza. Algumas das críticas mais contundentes de Benjamin aos modos de pensar a história se dirigem a Wilhelm Dilthey, uma das principais fontes de inspiração de Turner, e a Franz Leopoldo Ranke, que serviu de modelo de historiografia para Dilthey. ${ }^{6}$ No questionamento de Benjamin aos usos da empatia para fins de compreender o passado, detecta-se o ataque a Dilthey e a seus procedimentos hermenêuticos." Ao perguntar "com quem o investigador historicista estabelece uma relação de empatia”, o próprio Benjamin (I985g: 225, ênfase do autor) responde, de forma inequívoca: "com o vencedor. Ora, os que num dado momento dominam são os herdeiros de todos os que venceram antes". ${ }^{8}$ Enquanto Dilthey (2006: 49) tece elogios a Ranke, dizendo que "ele só procura reapresentar aquilo que foi", Benjamin anota: "A historiografia que mostrou 'como as coisas efetivamente aconteceram', foi o narcótico mais poderoso do século" (Benjamin, 2006: 505).9

Há grandes diferenças entre Benjamin e Turner. Abrem-se alguns abismos. Mas, como veremos a seguir, as afinidades também chamam a atenção. Três delas se evidenciam neste ensaio: I) ao realizarem uma arqueologia da experiência, Turner encontra a experiência do liminar, e Benjamin a grande tradição narrativa; 2) ao discutirem transformações que acompanham o capitalismo industrial, Turner fala de um sparagmos, ou desmembramento das formas de ação simbólica; e Benjamin da ruína da experiência e do estilhaçamento da tradição; e 3) na busca por formas de reconstituir uma experiência, as atenções de Turner se dirigem às formas liminóides de ação simbólica, e as de Benjamin às novas formas narrativas. Em relação a cada uma dessas afinidades, emergem questões capazes de nos fazer repensar algumas das formulações da antropologia da experiência e da performance. No fundo de cada questão, lampeja a imagem de Tonantzin. 


\section{PRIMEIRA AFINIDADE: LIMINARIDADE E A GRANDE TRADIÇÃO NARRATIVA}

Nos escritos dos dois autores nos deparamos com uma arqueologia da experiência. Em Turner, a discussão da experiência de liminaridade e communitas que se manifesta com força maior em sociedades que não passaram pela revolução industrial. Em Benjamin, a análise da grande tradição narrativa que se associa ao mundo da produção artesanal, e aos deslocamentos de contadores de histórias no tempo e no espaço.

No ensaio sobre Hidalgo, Victor Turner volta as suas atenções para a história. E para um momento marcante de experiência coletiva. Sob o signo da antropologia de Turner, o levante de Hidalgo se configura na história como momento liminar. História vira rito de passagem. Em momentos como esses, formam-se símbolos poderosos. Um dos gestos de Hidalgo chama a atenção: o erguimento da bandeira de Nossa Senhora de Guadalupe. Em torno dessa imagem de devoção associada ao catolicismo criollo e indígena se unificam grupos díspares do corpo social, manifestando, segundo o autor, profundos anseios por communitas. ${ }^{\text {Io }}$

No final do ensaio, após falar da relevância das categorias de "campo" e "arena" (caso se fizesse um estudo "sério" sobre Hidalgo), o retorno à questão da história. E uma discussão sobre relações entre passado e presente. Na formação da memória de intelectuais criollos, fulguram imagens associadas aos conquistadores espanhóis. A principal delas, a instituição do cabildo - que, segundo o pensamento criollo, regia as relações entre reis e conquistadores, e servia de alento às forças democratizantes em luta contra a tirania (Turner, I974d: I43; 2008d: I32). Entre criollos radicais, aliados a povos indígenas, lampejam imagens da Reconquista de Portugal, produzindo uma curiosa inversão: espanhóis adquirem as feições de mouros invasores (Turner, I974d: I49; 2008d: I37). Na população indígena também irrompem imagens de paisagens arcaicas, de um tempo anterior à chegada dos espanhóis. A matéria incandescente desses estratos energiza o gesto de Hidalgo.

A questão da história será retomada por Turner em escritos posteriores. Na introdução de From ritual to theatre (I982b: I3-I4), sob inspiração de Wilhelm Dilthey, aparece um primeiro esboço de uma antropologia da experiência. Tendo em mente a noção de Erlebnis (frequentemente traduzida como "vivência" ou "experiência vivida"), Turner fala de um processo constituído por cinco momentos: I) algo acontece a nível da percepção, provocando uma aguda sensação de dor ou prazer; 2 ) imagens de experiências passadas são evocadas; 3) emoções associadas a essas experiências do passado são revividas; 4) um sentido (meaning) é gerado na medida em que conexões se estabelecem, fazendo com que o passado e o presente entrem, conforme uma expressão de Dilthey, em uma "relação musical"; e 5) a experiência se completa através de uma forma de expressão. Daí, a noção de performance. Evo- 
cando uma etimologia que remete ao termo parfournir, do antigo francês, Turner (I982e: 9I) propõe que performance seja pensada, a partir de uma perspectiva processual, como uma forma expressiva que "completa" ou "realiza" uma experiência. A antropologia da performance faz parte de uma antropologia da experiência.

Em "Dewey, Dilthey e drama..." (I986), a partir da noção de Erlebnis (de Dilthey), Turner faz uma distinção entre "mera experiência" e "uma experiência". Erlebnis - "vivência" ou "experiência vivida" - refere-se a uma experiência marcante. ${ }^{\text {Ir }}$ Ao mesmo tempo, observa-se como Turner, na elaboração de sua própria concepção de experiência, inclui entre as suas fontes (como o título do seu ensaio enuncia), não apenas Dewey e Dilthey, mas, também, a noção de "drama", ou seja, a de "drama social" - o conceito desenvolvido pelo próprio Turner nos anos 1950, em Schism and continuity in an African society (I996 [1957]). Haveria em Turner a busca por um conceito mais amplo de experiência, capaz de evocar com força as dimensões coletivas do vivido? ${ }^{\mathrm{1} 2} \mathrm{Ha}$ veria uma nostalgia pelo tipo de experiência que se expressa de forma mais adequada no conceito de Erfahrung, do que no de Erlebnis? ${ }^{\text {13 }}$

Seria a noção de Erfahrung mais propícia do que a de Erlebnis para expressar as dimensões coletivas da experiência discutidas por Turner no ensaio sobre Hidalgo? Ali também - ao discutir a Insurreição de Hidalgo - as atenções do autor se dirigem aos dramas sociais. E, nesse caso, aos que se apresentam no palco da história.

Em "O narrador", Walter Benjamin discute experiência (Erfahrung) como fonte da grande tradição narrativa. Experiência tem a ver com a figura de quem viaja. Tal como o marinheiro, que vem de longe e tem histórias para contar. Ou, também, como o camponês sedentário que se afunda no tempo e nas histórias e tradições de um lugar de onde jamais saiu (Benjamin, I985f: I98-I99). Experiência associa-se ao deslocamento no tempo e no espaço. Erfahrung, diz Jeanne Marie Gagnebin (I994: 66), "vem do radical fahr - usado no antigo alemão no seu sentido literal de percorrer, de atravessar uma região durante uma viagem".

Saltam aos olhos as afinidades com as discussões de Turner. Na introdução de From ritual to theatre e no ensaio "Dewey, Dilthey e drama", Turner discute a etimologia da palavra "experiência", que deriva do termo indo-europeu *per-, "tentar, aventurar, arriscar". Os cognatos germânicos de per, que envolvem a transformação da letra $p$ em $f$, remetem ao radical fahr, discutido por Gagnebin. O termo grego perao, diz Turner (I986: 35), evoca a ideia de "passagem", ou rito de passagem. Em grego e latim, experiência tem a ver com "perigo, pirata, e ex-per-imento". Embora se inspire nos escritos de Dilthey sobre Erlebnis, Turner se aproxima, em sua etimologia da experiência, da noção de Erfahrung. Acima de tudo, Erfahrung evoca a experiência coletiva do liminar - uma ideia-chave para Benjamin e Turner. 


\section{SEGUNDA AFINIDADE: SPARAGMOS E O ESTILHAÇAMENTO DA TRADIÇÃO}

Em Turner e Benjamin, as marcas do romantismo: a constatação de um empobrecimento provocado ou agravado por forças do capitalismo industrial. Benjamin discute o estilhaçamento da tradição e a ruína da experiência. Turner fala de um sparagmos, ou desmembramento das formas de ação simbólica. E do enfraquecimento da experiência do liminar.

Tonantzin, uma imagem que se afunda no esquecimento. Nos escombros que se alojam sob a superfície onde ocorre o culto a Nossa Senhora de Guadalupe, ela se encontra. Segundo o pensamento de criollos radicais como Hidalgo, a colonia é uma fraude (Turner, I974d: I48; 2008d: 136). A conquista, a cena de um crime. Na história monumental de heróis e conquistadores, a catástrofe. No massacre de Alhóndiga que assombra o percurso trágico de Hidalgo (Turner, I974d: II4-II5; 2008d: I06-I07), ressoam, como em uma arena de vingança, os ecos de vozes emudecidas do passado. ${ }^{\mathrm{I4}}$ São os ecos do massacre, ou genocídio, da conquista da América. ${ }^{15}$ Prenúncios de massacrifícios do século 20 (ver Todorov, I99I: 248) - vividos de perto por Benjamin. ${ }^{16}$ Num cenário como esse, a própria ideia de sacrifício que Turner associa à figura de Hidalgo empalidece e parece perder sentido.

Esfacelamento da experiência. Em “O narrador", Benjamin (I985f: 197I98) observa que os combatente da Primeira Guerra Mundial "voltavam mudos do campo de batalha não mais ricos, e sim mais pobres em experiência comunicável". O que dizer, então, da experiência da conquista e da colonia para os povos indígenas do México? Em "Experiência e pobreza", Benjamin (I985C: II4-II5) lança uma série de questões:

Quem encontra ainda pessoas que saibam contar histórias como elas devem ser contadas? Que moribundos dizem hoje palavras tão duráveis que possam ser transmitidas como um anel, de geração em geração? Quem é ajudado, hoje, por um provérbio oportuno? Quem tentará, sequer, lidar com a juventude invocando sua experiência?

Com a chegada dos espanhóis, Tzvetan Todorov diz, os deuses se calam. "Os astecas [...] descrevem o início de seu próprio fim como um silêncio que cai: os deuses não lhes falam mais" (Todorov I991: 59). Na narrativa de Robert Ricard, citada por Turner, uma constatação: os tempos e lugares de rememoração associados a Tonantzin encontram-se soterrados.

Há tradições que caem no silêncio - junto aos corpos de seus narradores.

Todos os que até hoje venceram participam do cortejo triunfal, em que os dominadores de hoje espezinham os corpos dos que estão prostrados no chão. Os despojos são carregados no cortejo, como de praxe. Esses despojos são os que chamamos bens culturais. O materialista histórico os contempla com distanciamento. Pois todos os bens culturais que ele vê têm uma origem sobre a qual ele não pode refletir sem horror (Benjamin, 1985g: 225). 
Evocando a experiência de horror da época e do lugar em que viveu que não deixa de sugerir semelhanças com a de outros tempos e lugares Benjamin (I985g: 226) escreve: "A tradição dos oprimidos nos ensina que o 'estado de exceção' em que vivemos é na verdade a regra geral”. Com Turner, aprendemos que, em momentos extraordinários, de exceção e suspensão de regras - tais como acontecem em ritos e festas - o cosmos se renova. Tradições se revitalizam. Porém, o que dizer dos ritos e festas que comemoram o terror, diante dos corpos soterrados ou "prostrados no chão"? ${ }^{17}$ Sob o signo do horror, a exceção vira a regra. E o espantoso cotidiano.

As palavras e as coisas perdem sentido. Os sentidos são amortecidos. Interminável incerteza. Como reconstituir os sentidos do mundo? Diante do esfacelamento de uma tradição narrativa, como recompor a experiência?

Questões afins aparecem nos escritos de Victor Turner. Em "Dewey, Dilthey e drama...", escrevendo sob o signo de uma tragédia que atinge o mundo moderno - e se manifesta com força particularmente após a Revolução Industrial - Turner (I986: 42) fala de um sparagmos, ou desmembramento, de gêneros expressivos. ${ }^{18}$ Acompanhando a fragmentação das relações humanas, as formas de significar o mundo também se dispersam. Em meio a teias de significado que se fragilizam, ou se rompem, cai sobre o indivíduo a tarefa de encontrar o sentido das coisas. Observa-se o enfraquecimento da experiência liminar. Em "From liminal do liminoid...", Turner (I982C) mostra como, em sociedades industriais, as atividades humanas se separam em esferas do trabalho e do lazer. Às margens das atividades consideradas mais importantes da vida social, surgem gêneros liminóides. O sufixo grego oid (derivado de eidos - "uma forma de", ou "parecido com") denota a semelhança. E a diferença (ver Turner, I982c: 32). Expressões liminóides se caracterizam pela perda de poderes de recriação de universos sociais e simbólicos que se associam a experiências de liminaridade e communitas.

Em diversos escritos, Turner (I982f: I04-I05, I08; I987b: 22, 24) compara as performances ou formas expressivas geradas por uma experiência a espelhos mágicos. Creio que essa imagem é sugestiva para discutir a passagem do liminar ao liminóide. Se, na experiência liminar, temos algo como um grande espelho mágico - ou uma espécie de "espelhão" coletivo -, a experiência liminóide pode sugerir uma dispersão de espelhos. Ou, mesmo, um estilhaçamento. ${ }^{19}$ Chama a atenção, nesse caso, o amontoado de cacos.

A noção de Erlebnis, que Turner encontra em Dilthey, denota o empobrecimento. Ao mesmo tempo em que ela evoca algo do extraordinário, a ideia de Erlebnis também pode sinalizar a redução da experiência ao plano do indivíduo e da subjetividade humana. Uma concepção de experiência que se inscreve na temporalidade de uma tradição compartilhada, tal como a que se evoca com a palavra Erfahrung, se atenua, ou se dissolve (Gagnebin, I994: 66). 
Mesmo assim, há esperanças na Erlebnis. Em "Dewey, Dilthey e drama...", Turner (1986: 35-36, tradução minha) descreve os momentos iniciais de uma estrutura de experiência:

Essas experiências que irrompem de ou interrompem comportamentos repetitivos e rotinizados se iniciam com choques de dor ou prazer. Tais choques são evocativos: eles invocam precedentes ou semelhanças com o passado consciente ou inconsciente - pois, assim como o usual, o inusitado também tem as suas tradições. Então as emoções de experiências passadas dão cor às imagens e aos esboços revividos pelo choque do presente..$^{20}$

Em "Sobre alguns temas em Baudelaire", Benjamin também chama a atenção para o choque da experiência contemporânea. A partir de sua leitura de Freud (em Além do princípio do prazer), Benjamin (I995: I Io) sugere que, na experiência vivida (Erlebnis), o choque tende a ser amortecido e aparado pela atividade do consciente. Assim se produz o esquecimento.

A discussão de Marcel Proust a respeito da memória involuntária marca o pensamento benjaminiano. ${ }^{21}$ Nas histórias que as pessoas contam para si sobre elas mesmas, através de suas reminiscências intencionais, algo se desfaz. Ao falar do tecido da memória, Benjamin evoca a bela imagem de Penélope da epopeia de Ulisses. À noite Penélope desfaz o que ela teceu ao longo do dia. Mas, talvez a memória, sugere Benjamin (I985b: 37), opere de modo inverso. "Pois aqui é o dia que desfaz o trabalho da noite". Dos fundos da memória involuntária, e de suas oficinas noturnas, irrompem as imagens das histórias do esquecimento. Em um ensaio sobre Franz Kafka, Benjamin (I985d: I62) escreve: "Pois o que sopra dos abismos do esquecimento é uma tempestade".

Retornamos à questão do sparagmos, ou desmembramento de formas de ação simbólica. Haveria aqui os indícios de um processo de esquecimento? Em "Dewey, Dilthey e drama...", após a sua discussão de sparagmos, Turner (I986: 43) sugere uma oposição significativa entre os termos em inglês - dismember (desmembrar) e re-member (rememorar). ${ }^{22}$ Em outro texto, o autor (I982d: 86) escreve, numa frase que também parece evocar um trabalho de Penélope: "Desmembramento (dismembering) pode ser um prelúdio para re-memoração (re-membering)". ${ }^{23}$

Observa-se em Turner a atenção para os movimentos do inconsciente. Em From ritual to theatre, o autor escreve: "Eu iria mais longe que Dilthey e veria muitos atos como modos de expressar e realizar propósitos e metas inconscientes" (Turner I982b: I5, ênfases do autor). ${ }^{24}$

No ensaio sobre Hidalgo, Turner explora as dimensões inconscientes dos movimentos sociais. A história trágica de Hidalgo desperta dos fundos de uma memória coletiva um paradigma do martírio. Porém, mais do que o final trágico da história, chama a atenção o gesto de Hidalgo levantando a bandeira de Nossa Senhora de Guadalupe. Uma insurreição ganha os contor- 
nos de uma experiência primária. ${ }^{25}$ Questões não resolvidas vêm à superfície. Anseios sufocados ganham expressão. De imediato, aparentemente, esses anseios não se referem à communitas, ou ao espírito de comunhão entre indígenas, criollos e gachupines. ${ }^{26}$ No gesto de Hidalgo, irrompe a Nossa Senhora de Guadalupe. Uma "mãe dolorosa" se transforma, e adquire as qualidades de Tonantzin - também conhecida (conforme registros de Sahagun) como mãe terra, senhora da guerra e mulher serpente. ${ }^{27} \mathrm{Em}$ Dolores ouve-se o grito de um parto - mas, é a própria mãe que renasce. Relampeia a imagem de mãe que insurge contra os que maltratam os filhos da terra. Na imagem de Nossa Senhora, revela-se a "mãe dolorosa" cujos filhos se encontram em via crucis. Dos seus fundos, vem o "grito de Dolores". Ele vem de Tonantzin. Uma questão benjaminiana: seria esse grito uma expressão da vontade de interromper o curso da história? E fazer cessar os ciclos intermináveis de ritos sacrificiais? E as ondas sucessivas de massacres e massacrifícios? História como catástrofe. Haveria no gesto de Hidalgo, erguendo a bandeira de Nossa Senhora de Guadalupe, a expressão da memória involuntária de uma população formada por índios e criollos? Nas oficinas obscuras da memória fulgura, entre as suas obras, a imagem de Tonantzin. Nas dobras de outra, à luz do dia, ela se oculta. Como um corpo encoberto que fricciona a persona do sagrado ela se manifesta.

De acordo com Turner, o sentido de uma experiência é gerado, como visto, na medida em que conexões se estabelecem, fazendo com que o passado e o presente entrem (como diria Dilthey), em uma "relação musical". Em Dolores, essa relação se estabelece na forma de um grito.

\section{TERCEIRA AFINIDADE: FENÔMENOS LIMINÓIDES}

\section{E NOVAS FORMAS NARRATIVAS}

Na busca por formas de reconstituir uma experiência, uma terceira afinidade. Enquanto as atenções de Turner se dirigem às formas liminóides de ação simbólica, as de Benjamin se voltam às novas formas narrativas.

A apresentação de Dramas, fields and metaphors marca uma inflexão na antropologia de Victor Turner. Nem tanto pela discussão inicial das categorias enunciadas no título do livro, mas por um breve comentário introduzindo a noção do liminóide. Turner (2008b: 14; 1974b: I6) escreve:

Sugeriria que o que temos considerado como os gêneros "sérios" de ação simbólica

- ritual, mito, tragédia e comédia (no seu "nascimento") - encontram-se profundamente implicados nas visões cíclicas e repetitivas do processo social, enquanto os gêneros que surgiram desde a Revolução Industrial (as artes e ciências modernas), embora menos sérias aos olhos das pessoas comuns (pesquisa pura, entretenimento, interesses da elite), tiveram um maior potencial para mudar a maneira como os ho- 
mens se relacionam um com os outros e o conteúdo dos seus relacionamentos. A in-
fluência destes últimos tem sido mais insidiosa. Porque eles estão fora das arenas de
produção industrial direta, pois constituem os análogos "liminóides" dos fenômenos
e processos liminares nas sociedades tribais e agrárias primitivas, seu próprio outsi-
derhood os libera da ação funcional direta nas mentes e no comportamento dos mem-
bros de uma sociedade. Ser o ator ou audiência é uma atividade opcional - a falta de
obrigação e coação por normas externas lhes confere uma qualidade prazerosa que
os torna capazes de serem absorvidos mais prontamente pela consciência individual.
O prazer torna-se então, uma questão crucial no contexto das mudanças inovadoras. ${ }^{28}$

Turner (2008b: I4-I5; I974b: I6) continua:

Neste livro, não abordei esta questão, porém, minha preocupação com sociedades complexas em mutação (Inglaterra do século XII, México do século XIX, Índia medieval, Europa e Ásia medievais e modernas enquanto palco de processos de peregrinação) aponta na direção desta formulação. ${ }^{29}$

No ensaio sobre Hidalgo, não encontramos referências explícitas a processos liminóides. Ao contrário, a insurreição de Hidalgo é vista como parte de um período liminar da história mexicana. Trata-se, conforme diz o autor (Turner I974d: 99; 2008d: 92), de um drama social que inaugura o rito de passagem de um povo submetido ao domínio colonial para uma condição de nação independente. Mas, elementos liminóides claramente se manifestam. Merece destaque a breve descrição das atividades do Clube Social e Literário de Querétaro, de qual participavam o Padre Miguel Hidalgo e outros conspiradores. Nesse clube criollos radicais discutiam doutrinas dos enciclopedistas e da Revolução Francesa, e, possivelmente, a aplicação de doutrinas de jesuítas (tais como as de Franciso Suarez) a questões de soberania política (Turner I974d: I02-103; 2008d: 95). Observa-se que os conspiradores planejavam dar início à insurreição na festa da Virgem de Candelária, no dia 8 de dezembro, em San Juan de los Lagos. Mas, quando esses planos foram descobertos por autoridades espanholas ou gachupines ("esporas"), a insurreição irrompeu em Dolores. Foi ali, na paróquia de Hidalgo, que ocorreu o "Grito de Dolores".

Ao falar de fenômenos liminóides, no prefácio de 1974, Turner deu mais ênfase a gêneros "menos sérios" de ação simbólica - incluindo, como exemplos, "pesquisa pura, entretenimento, interesses da elite". No ensaio "From liminal to liminoid...", Turner (I982c: 54-55) amplia o leque desses fenômenos, que passam a incluir "críticas sociais e manifestos revolucionários" - como os do Clube Social e Literário de Querétaro. Insurreições e revoluções têm afinidades com experiências liminóides (Turner I982C: 45).

Em cinco itens, resumidos a seguir, Turner (1982C: 53-55) discute diferenças entre fenômenos liminares e liminóides. I) Ao passo que fenômenos liminares tendem a predominar em sociedades tribais e agrárias caracterizadas, conforme o termo de Durkheim, por modos de "solidariedade mecânica", fenômenos liminóides florescem em sociedades baseadas em princípios de "solidariedade orgânica", com relações contratuais. 2) Fenômenos liminares tendem 
a ser de natureza cíclica e coletiva. Fenômenos liminóides, por sua vez, geralmente se manifestam como produtos individualizados, mesmo que tenham efeitos coletivos ou afetem as "massas" sociais. Embora não sejam cíclicos, são continuamente produzidos, particularmente em tempos e espaços separados do trabalho e designados como sendo de "lazer". 3) Fenômenos liminares "se integram centralmente ao processo social total, compondo um todo completo, e representando os seus aspectos necessariamente negativos e subjuntivos". Em contrapartida, "fenômenos liminóides se desenvolvem à parte dos processos econômicos e políticos centrais, às suas margens, nas interfaces e nos interstícios das instituições". Trata-se de fenômenos plurais, fragmentários e experimentais. 4) Fenômenos liminares tendem a se apresentar de modo parecido com as "representações coletivas" discutidas por Durkheim, como símbolos que têm um sentido intelectual e emocional comum para todos os membros do grupo. Eles refletem a história do grupo, a sua experiência coletiva ao longo do tempo. Fenômenos liminóides, porém, por serem mais individualizados, tendem a gerar símbolos de ordem mais pessoal ou psicológica do que objetiva e social. 5) Fenômenos liminares tendem a ser "eufuncionais", reduzindo fricções na estrutura social, mesmo quando suscitam efeitos de inversão. Fenômenos liminóides, por outro lado, "frequentemente se associam a críticas sociais ou, até mesmo, manifestos revolucionários - livros, peças teatrais, pinturas, filmes etc. expondo injustiças, ineficiências ou quebras de padrões morais".

Diante do enfraquecimento da experiência do liminar, Turner volta as suas atenções para as expressões liminóides. Por sua vez, em face da degradação da grande tradição narrativa, Benjamin toma interesse por novas formas narrativas. Em "A obra de arte na era de sua reprodutibilidade técnica", Benjamin (1985e) explora, no cenário devastado de sua (nossa) época, as possibilidades para reconstituição da experiência que se abrem com o cinema e a fotografia. E se interessa por movimentos de vaguardas artísticas. No surrealismo, no dadaísmo, nas histórias de Kafka, nas pinturas de Klee, no teatro épico de Brecht, e em muitas outras manifestações artísticas de seu tempo, Benjamin encontra elementos que evocam a grande tradição narrativa. Gagnebin (1985: 12) escreve:

Essas tendências "progressistas" da arte moderna, que reconstroem um universo incerto a partir de uma tradição esfacelada são, em sua dimensão mais profunda, mais fiéis ao legado da grande tradição narrativa que as tentativas previamente condenadas de recriar o calor de uma experiência coletiva ("Erfahrung") a partir das experiências vividas isoladas ("Erlebnisse"). Essa dimensão, que me parece fundamental na obra de Benjamin, é a de abertura.

Como exemplo dessa tradição, um trecho da narrativa de Heródoto, analisada por Benjamin em "O narrador": 
Heródoto não explica nada. Seu relato é dos mais secos. Por isso, essa história do antigo Egito ainda é capaz, depois de milênios, de suscitar espanto e reflexão. Ela se assemelha a essas sementes de trigo que durante milhares de anos ficaram fechadas hermeticamente nas câmaras das pirâmides e que conservam até hoje suas forças germinativas (Benjamin I985f: 204).

No surrealismo, Benjamin (I985a: 32, 33) encontra um imperativo: "mobilizar para a revolução as energias da embriaguez". E descobre na dialética do olhar uma iluminação profana: "De nada nos serve a tentativa patética ou fanática de apontar no enigmático o seu lado enigmático; só devassamos o mistério na medida em que o encontramos no cotidiano, graças a uma ótica dialética que vê o cotidiano como impenetrável e o impenetrável como cotidiano" (Benjamin I985a: 33).30

Chama a atenção o duplo estranhamento: em relação ao cotidiano e ao extraordinário (ou impenetrável) também. Seria uma pista importante para entender as dimensões subversivas apontadas por Turner nos fenômenos liminóides? ${ }^{31}$ As formulações do autor, acima referidas, merecem atenção. Turner diz: "fenômenos liminóides se desenvolvem à parte dos processos econômicos e políticos centrais, às suas margens, nas interfaces e nos interstícios das instituições". Ao passo que fenômenos liminares "se integram centralmente ao processo social total", os fenômenos liminóides ficam às margens. Ou seja, configura-se no liminóide a possibilidade de um duplo deslocamento, às margens das margens. Ao passo que o fenômeno liminar, enquanto experiência do extraordinário, tende a produzir o estranhamento em relação ao cotidiano, o fenômeno liminóide é capaz de produzir um duplo estranhamento, às margens inclusive da experiência do extraordinário. Se a expressão liminar frequentemente revela os usos das margens para fins de revitalizar processos centrais, o fenômeno liminóide, em suas manifestações mais críticas, se mantém às margens das margens.

Daí, acredito, a força do duplo deslocamento que se revela no ensaio de Turner: de Hidalgo para Nossa Senhora de Guadalupe, e de Nossa Senhora para Tonantzin. Em peregrinações e festas de louvor a Nossa Senhora, como Turner (I974e; 2008d) demonstra, o cotidiano se revela como extraordinário, numinoso e enigmático. Índios e criollos, como personae de um drama de proporções cósmicas, são iluminados como filhos da Virgem Mãe. Mas, não haveria no gesto de Hidalgo, e no "grito de Dolores", às margens da festa, uma segunda iluminação que ocorre de modo inverso - a revelação de Nossa Senhora como mãe de criollos e índios? Tonantzin. Aqui quem faz o rito de passagem é a Nossa Senhora, saindo do espaço do sagrado para o cotidiano, ou lugar profano, vivido como límen. Em momentos como esses a própria santa se coloca em estado de risco, tornando-se mulher perigosa. ${ }^{32}$ Sob a luz profana, o seu corpo tem cor. Na ótica dialética, a mãe dos deuses provoca uma iluminação profana. E produz a inervação de um corpo social. 
Nas vanguardas do início do século 20 - no dadaísmo, no surrealismo, no teatro épico de Brecht, e nos experimentos do cinema - Benjamin também descobre a ideia da montagem. Para fins deste ensaio, chama a atenção em seus escritos a noção de montagem em forma de choque, capaz de produzir efeitos de despertar (Bolle, I994: 97). Segundo Eisenstein, a montagem envolve a justaposição de planos em conflito. "O que, então, caracteriza a montagem, e, consequentemente, sua célula - o plano? A colisão. O conflito de duas peças em si. O conflito. A colisão" (Eisenstein, I990: 4I). Aquém (ou além) do símbolo, uma montagem revela os resíduos, ruídos e aspectos não resolvidos da vida social. Em ilusórias totalidades, ela faz emergir a cesura. Os seus efeitos em um todo supostamente coeso ou harmonioso podem ser explosivos.

Talvez não haja diferença maior do que essa entre a antropologia de Victor Turner e o pensamento benjaminiano. Em ambos, o olhar se dirige aos momentos de interrupção. Em Turner a ruptura se transforma em transição reconstituindo e revitalizando o todo - tal como acontece num rito de passagem. No caso de Hidalgo, o próprio continuum da história se revitaliza. Em Benjamin (I985g: 230, 23I), a "imobilização messiânica dos acontecimentos". E, numa "configuração saturada de tensões", uma imagem faz explodir o continuum da história. ${ }^{33}$ Desconfia-se dos efeitos narcotizantes de uma história que se mantém através de suas vítimas sacrificiais - como Hidalgo, em cujos atos Turner (I974d: I22-I24; 2008d: II3-II5) detecta o retorno de um paradigma do martírio. Dos resíduos da história irrompem imagens que se articulam ao presente em forma de montagens carregadas de tensões.

Em Benjamin, as atenções se voltam às montagens. Em Turner, aos símbolos. No entanto, como o ensaio sobre Hidalgo revela, os símbolos têm os seus subterrâneos. ${ }^{34} \mathrm{O}$ culto a Nossa Senhora de Guadalupe se realiza no Morro de Tepeyac, sobre os escombros do antigo culto a Tonantzin, destruído pelos espanhóis. Seria Tonantzin uma manifestação do baixo corporal de Nossa Senhora de Guadalupe? Em seus lugares mais fundos e fecundos, os símbolos se decompõem em montagens.

Observa-se o percurso de Tonantzin no ensaio de Turner. Na página I05 da edição em inglês (ver página 98 da edição brasileira), a oito páginas do início do texto, ela aparece numa citação, conforme dito, tomando o leitor de assalto. Em páginas subsequentes há discussões sobre Nossa Senhora de Guadalupe - na página ro6 (ver página 99), como símbolo capaz de evocar o passado indígena; na página I 7 (ver página I08), como imagem que se contrapõe à da Virgem de Remédios; na página 22 (ver página II3), como nome que retorna, numa ironia da história, no fim trágico de Hidalgo em Nuestra Señora de Guadalupe de Baján; na página I4I (ver página I3I), como símbolo que mobiliza índios e criollos; e, na página I50 (ver página I38), como símbolo sensorialmente perceptível - sem nenhuma menção explícita a Tonantzin. Porém, na página I5I (ver página I39), a duas páginas do final do ensaio, a 
imagem de Tonantzin retorna. Informações referentes à citação da página I05 (ver página 98) são retomadas.

Nossa Senhora de Guadalupe tinha uma continuidade espacial com Tonantzin, a mãe dos deuses asteca. Seu culto tinha começado apenas I5 anos depois de o culto da Senhora asteca ter sido interrompido à força pela Conquista. Ademais, de acordo com a história conhecida por todo o México, em I8Io, a Rainha dos Céus visitara a terra para encontrar-se com um índio catecúmeno, Juan Diego, e não com um espanhol, e muito menos com um religioso espanhol (Turner, 2008: I39). ${ }^{35}$

Em seguida, uma formulação curta, em forma de montagem: "Maria-Tonantzin" (Turner, I974d: I52; 2008d: I40).

$\mathrm{Na}$ virada da página, a montagem se desfaz. O ensaio termina com a discussão de Nossa Senhora de Guadalupe como um símbolo "criollo-indígena" (I974d: I53; 2008d: I4I). Em lugar de Maria-Tonantzin, simplesmente Maria. A imagem de Tonantzin novamente se afunda.

O trabalho de unificação realizado por um símbolo pode produzir esquecimento? Ao explorar os subterrâneos do símbolo, Victor Turner suscita um efeito surpreendente. Um símbolo se transforma em montagem, e, com efeitos de despertar, uma imagem irrompe da memória involuntária. Haveria aqui uma afinidade eletiva entre um gesto e outro, de Victor Turner e de Miguel Hidalgo? Nos dois casos, uma bandeira se levanta. Acima de tudo, porém, chama atenção o duplo deslocamento - de Hidalgo para Nossa Senhora de Guadalupe, e de Nossa Senhora para Tonantzin.

\section{PASSAGENS}

Como dito, essa releitura do ensaio de Turner sobre Hidalgo surge de um assalto: uma citação onde lampeja a imagem de Tonantzin. No ensaio de Turner, encontrei um momento originário, um remoinho onde surgem elementos que compõem uma antropologia da experiência e da performance. Em remoinhos resíduos também vêm à superfície, sugerindo antropologias que ainda não vieram a ser. Nas margens interiores da antropologia de Turner, o pensamento benjaminiano pode despertar interesse. E revelar alguns dos elementos mais surpreendentes (como as sementes de quais fala Heródoto) dos escritos de Turner.

Explorando afinidades entre Turner e Benjamin procurei reler o ensaio do primeiro sobre Hidalgo. Mais do que conclusões, permanecem as questões. I. Haveria na antropologia de Victor Turner uma constatação, ainda que não declarada, da insuficiência da noção de experiência que se revela na Erlebnis? Seria a ideia de Erfahrung mais apropriada para expressar os anseios que se revelam nos seus esboços de uma antropologia da experiência? No ensaio sobre Hidalgo chama a atenção a profundidade de uma experiência coletiva. E a força de imagens que se manifestam como resíduos do seu esfacelamento. 
2. No sparagmos, ou desmembramento de formas de ação simbólica, sobre qual fala Victor Turner, se manifesta a história de um esquecimento. E os choques de um espanto cotidiano. Seria Tonantzin uma imagem que irrompe da memória involuntária provocando, com efeitos de pasmo, o despertar de uma bela adormecida?

3. Quando passado e presente entram em uma "relação musical", diz Dilthey, gera-se o sentido de uma experiência. Em Dolores essa relação se estabelece na forma de um grito. Assim irrompe da paisagem sonora uma das vozes emudecidas do passado, provocando a inervação dos sentidos de um corpo social. As atenções do antropólogo se voltam aos movimentos surpreendentes do mundo sensível - e aos sussurros, ruidos e gritos que se alojam em camadas do inconsciente sonoro.

4. Chama a atenção o duplo deslocamento que se revela no ensaio de Turner: de Hidalgo a Nossa Senhora de Guadalupe, e de Nossa Senhora a Tonantzin. Em processos liminares, elementos estruturalmente arredios contribuem para a revitalização de processos estruturantes. Haveriam nas formas liminóides elementos que emergem às margens de processos liminares? Seriam eles capazes de suscitar, às margens das margens, conforme os requisitos de uma ótica dialética, um duplo estranhamento, em relação ao cotidiano e ao extraordinário também?

5. Em subterrâneos das formas expressivas, símbolos se decompõem em montagens carregadas de tensões. Assim se manifesta Maria-Tonantzin. Uma imagem do passado se articula ao presente em um momento de perigo. No gesto de Hidalgo observa-se a força irruptiva capaz de fazer explodir o continuum da história.

Como dito anteriormene, a proposta de explorar afinidades entre Benjamin e Turner pode causar estranheza. Em Turner, um efeito de cura se produz em momentos de ruptura e crise, revitalizando o continuum da história. Em Benjamin, busca-se a explosão do continuum. Em ambos, o foco no límen. No ensaio "Liminaridade e communitas", Turner (1977b) se detém no segundo momento do modelo de rito de passagem de Van Gennep, a experiência do liminar. Ali se encontra a possibilidade de communitas. Em Benjamin, o liminar adquire as feições de um espantoso cotidiano. Não há nada surpreendente no espantoso. No entanto, nas histórias de Nikolai Leskov - que levam as sementes da grande tradição narrativa - Benjamin (I985f: 216) encontra um princípio que irá nortear a sua própria obra: a apocatastasis, o dogma rejeitado de Orígenes de que todas as almas serão admitidas ao paraíso. "Somente para a humanidade redimida o passado é citável, em cada um dos seus momentos" (Benjamin I993f: 223) $\cdot^{36} \mathrm{Na}$ citação que deu origem a esse ensaio, como uma assaltante das passagens, apareceu Tonantzin. 
TONANTZIN: VICTOR TURNER, WALTER BENJAMIN E ANTROPOLOGIA DA EXPERIÊNCIA

394

John C. Dawsey é professor titular e livre-docente do Departamento de Antropologia da Faculdade de Filosofia, Letras e Ciências Humanas da Universidade de São Paulo (FFLCH/USP) e Coordenador do Núcleo de Antropologia, Performance e Drama (Napedra). É autor de De que riem os boias-frias? Por uma antropologia benjaminiana (no prelo). 


\section{NOTAS}

* Agradeço à Fundação de Amparo à Pesquisa do Estado de São Paulo (Fapesp) e ao Conselho Nacional de Desenvolvimento Científico e Tecnológico (CNPq), por apoios recebidos para o desenvolvimento desta pesquisa.

I "The cult of Our Lady of Guadalupe and the pilgrimage to Tepeyac - the hill near Mexico City on which the 'Brown Virgin' of Guadalupe is said first to have appeared to the Aztec Indian catechumen Juan Diego about ten years after the Spanish Conquest, and the hill, incidentally, on which the pre-Hispanic goddeess Tonantzin had been worshipped before Cortés arrived - seem [...] to have been born, grown up, and triumphed with the suport of the episcopate, in the face of [...] the turbulent hostility of the Friars Minor of Mexico". Trata-se de uma citação do livro The spiritual conquest of Mexico, de Robert Ricard (I966: I9I).

2 A imagem da lontra se inspira num dos fragmentos mais conhecidos de "Infância em Berlim", de Benjamin (I993b: 93-94).

3 Ou, melhor, em I970. O texto foi apresentado pela primeira vez no Departamento de Antropologia de Brandeis University, em abril de I970. Antes dessa data, Turner já havia publicado Schism and continuity in an African society, em I957; The forest of symbols, em 1967; The drums of affliction, em I968; e The ritual process, em I969.

4 "If I were, therefore, to make a serious anthropological study of the complete process of the Hidalgo Insurrection....". A tradução da edição brasileira (2008: I26) atenua o caráter subjuntivo da frase, preferindo a versão "se meu objetivo for" à "se meu objetivo fosse".

5 Benjamin (I993c: 85) escreve: "A crítica da obra é muito mais sua reflexão, que, evidentemente, pode apenas levar ao desdobramento do germe crítico imanente a ela mesma". E diz, também: "Está claro: para os românticos, a crítica é muito menos o julgamento de uma obra do que o método de seu acabamento" (Benjamin 1993c: 77).

6 Em From ritual to theatre, Turner (I982b: I8) escreve: "Em Charlottesville, Virginia, onde agora leciono na universidade, a frase 'Sr. Jefferson teria aprovado isso', representa o selo final de aprovação para qualquer ato. Imagino 
de modo correlativo que o 'Professor Dilthey teria aprovado' as tentativas de um punhado de antropólogos e de pesquisadores e praticantes do teatro de gerar uma antropologia e um teatro da experiência que busca 'compreender outros povos e suas expressões a partir da experiência e autocompreensão e da interação constante de ambas'”. ["In Charlottesville, Virginia, where I now teach at the university, the phrase 'Mr. Jefferson would have approved of that', is the final seal of approval for any action. I imagine correlatively that 'Professor Dilthey would have approved' of attempts being made by a handful of anthropologists and theatre scholars and practioners to generate an anthropology and theatre of experience which seek to 'understand other people and their expressions on the basis of experience and self-understanding and the constant interaction between them'".] A citação dentro da citação vem de Dilthey (2010: 2I8).

7 Dilthey escreve: "Se, portanto, a compreensão exige a presença de nossa própria experiência mental, isso pode ser descrito como uma projeção de si em alguma dada expressão. A partir dessa empatia ou transposição surge a forma mais elevada de compreensão em que está ativa a totalidade da vida mental - re-criação ou re-vivência. A compreensão como tal se move em direção inversa à sequência dos eventos. Mas a empatia plena precisa que a compreensão se mova de acordo com a ordem dos eventos para que possa manter passo com o curso da vida. Dessa maneira a empatia ou transposição se expande. A re-experiência segue a linha dos eventos. Progredimos com a história de um período, com um evento no exterior ou com processos mentais de uma pessoa próxima" (Dilthey 20I0: 226, tradução minha). ["If, therefore, understanding requires the presence of one's own mental experience this can be described as a projection of the self into some given expression. On the basis of this empathy or transposition there arises the highest form of understanding in which the totality of mental life is active - recreating or re-living. Understanding as such moves in the reverse order to the sequence of events. But full empathy depends on understanding moving with the order of events so that it keeps step with the course of life. It is in this way that empathy or transposition expands. Re-experiencing fol- 
lows the line of events. We progress with the history of a period, with an event abroad or with the mental processes of a person close to us" (Dilthey, 2010: 226).]

8 A empatia de Turner, me parece, se dirige particularmente às personagens nas quais se manifesta o "poder do fraco", e, nos casos de Hidalgo e Thomas Becket (ver Turner I974C; 2008C), os paradigmas do martírio.

9 Arquivo N3,4 de Passagens. "The history that showed things 'as they really were' was the strongest narcotic of the century" (Benjamin, I999: 463).

Io O termo criollo se refere a descendentes de espanhóis nascidos nas Américas (ver Turner, I974C: IOI; 2008c: 94). De acordo com Turner (I977b: I26-I27), communitas envolve uma experiência de comunhão, em que um vínculo mais fundo se estabelece entre pessoas sem a mediação dos papéis por elas desempenhados na estrutura social. Em momentos de suspensão desses papéis, ou de antiestrutura, a experiência de communitas pode irromper.

I I Rudolf A. Makkreel (I975: I47) escreve: "Erlebnis frequentemente se traduz como 'experiência vivida' para distinguí-la da experiência mais ordinária designada por Erfahrung" (tradução minha). ["Erlebnis is often translated as 'lived experience' to distinguish it from the more ordinary experience designated by Erfahrung".]

I2 Embora a noção de Erlebnis se refira particularmente à "experiência vivida" de um indivíduo, Dilthey não deixa de salientar como esse indivíduo é um ser social, e participa de uma experiência coletiva. Em sua leitura de Dilthey, Turner (I987d: 84) salienta justamente essa dimensão coletiva da experiência. "Para Dilthey a experiência consiste de um sistema que, embora coerente, apresenta múltiplas facetas, já que depende da interação e interpenetração da cognição, do afeto, e da volição. Ela inclui não apenas as nossas observações e reações, mas também a sabedoria acumulada da humanidade, que se expressa não somente nos costumes e na tradição, mas também nas grandes obras de arte (aqui, me refiro à sabedoria e não ao conhecimento, que é cognitivo em sua essência). Há um corpo vivo e crescente de experiência, uma tradição de communitas, digamos, que incorpora a resposta de 
nossa mente coletiva inteira toda a nossa experiência coletiva. Adquirimos essa sabedoria não através do pensamento abstrato solitário, mas pela participação imediata e vicária através de gêneros performativos em dramas socioculturais" (tradução minha). ["For Dilthey experience is a many-faceted yet coherent system dependent on the interaction and interpenetration of cognition, affect, and volition. It is made up of not only our observations and reactions, but also the cumulative wisdom (not knowledge, which is cognitive in essence) of humankind, expressed not only in custom and tradition but also in great works of art. There is a living and growing body of experience, a tradition of communitas, so to speak, which embodies the response of our whole collective mind to our entire collective experience. We acquire this wisdom not by abstract solitary thought, but by participation immediately or vicariously through the performance genres in sociocultural dramas".]

I3 Analisei essa questão em "Victor Turner e antropologia da experiência” (Dawsey, 2005).

I4 Benjamin (I985g: 228-229) escreve: "O sujeito do conhecimento histórico é a própria classe combatente e oprimida. Em Marx, ela aparece como a última classe escravizada, como a classe vingadora que consuma a tarefa de libertação em nome das gerações de derrotados. Essa consciência, reativada durante algum tempo no movimento espartaquista, foi sempre inaceitável para a social-democracia. Em três decênios, ela quase conseguiu extinguir o nome de Blanqui, cujo eco abalara o século passado. Preferiu atribuir à classe operária o papel de salvar gerações futuras. Com isso, ela a privou das suas melhores forças. A classe operária desaprendeu nessa escola tanto o ódio como o espírito de sacrifício. Porque um e outro se alimentam da imagem dos antepassados escravizados, e não dos descendentes liberados".

I5 Tzvetan Todorov (I99I: I29) escreve: "Sem entrar em detalhes, e para dar somente uma ideia global (apesar de não nos sentirmos totalmente no direito de arredondar os números em se tratando de vidas humanas), lembraremos que em I500 a população do globo deve ser da ordem de 400 milhões, dos quais 80 milhões habitam as 
Américas. Em meados do século XVI, desses 80 milhões, restam Io. Ou, se nos restringirmos ao México: às vésperas da conquista, sua população é de aproximadamente 25 milhões; em I60o, é de I milhão. Se a palavra genocídio foi alguma vez aplicada com precisão a um caso, então é esse."

I6 Todorov (I99I: I39-I40) escreve: “[...] caberia aqui falar em sociedades de sacrifício e sociedades de massacre, de que os astecas e os espanhóis do século XVI seriam, respectivamente, os representantes. O sacrifício é, nessa ótica, um assassinato religioso: faz-se em nome da ideologia oficial, e será perpetrado em praça pública, à vista e conhecimento de todos. A identidade do sacrificado é determinada por regras estritas. Não deve ser estrangeiro demais, afastado demais [...]. Os sacrificados provêm de países limítrofes [...]. Nem semelhante nem totalmente diferente [...]. O sacrifício é executado em praça pública, e evidencia a força dos laços sociais e seu predomínio sobre o ser individual. O massacre, ao contrário, revela a fragilidade desses laços sociais, o desuso dos princípios morais que asseguravam a coesão do grupo [...]. Quanto mais longínquos e estrangeiros forem os massacrados, melhor: são exterminados sem remorsos, mais ou menos assimilados aos animais. [...] A 'barbárie' dos espanhóis nada tem de atávico, ou de animal; é bem humana e anuncia a chegada dos tempos modernos". Em relação às sociedades de massacrifício, Todorov (I99I: 248-249) diz: "Num outro plano ainda, a experiência recente é desencorajadora: o desejo de ultrapassar o individualismo da sociedade igualitária e de chegar à sociabilidade própria das sociedades hierárquicas encontra-se, entre outros, nos Estados totalitários. [...] Esses Estados, certamente modernos, não podendo ser assimilados nem às sociedades de sacrifício e nem às sociedades de massacre, reúnem, no entanto, certos traços das duas, e mereceriam a criação de uma palavra mista: são as sociedades de massacrifício. Como nas primeiras, professa-se uma religião de Estado; como nas últimas, o comportamento está fundamentado no princípio karamazoviano do 'tudo é permitido'. Como no sacrifício, mata-se inicialmente em casa; como no caso dos massacres, oculta-se e nega-se a exis- 
tência dessas matanças. Como lá, as vítimas são escolhidas individualmente; como aqui, são exterminadas sem nenhuma ideia de ritual. O terceiro termo existe, mas é pior do que os dois precedentes; quê fazer?"

I7 Michael Taussig (I993) discute os usos da obscuridade epistemológica na política da representação da cultura do terror.

I8 A referência à Revolução Industrial pode evocar, no ensaio sobre Hidalgo, uma discussão a respeito de relações de trabalho e formas de produção nas Américas, anteriores à Revolução Industrial, na época da conquista. Escrevendo sobre os "maus-tratos", que, junto ao "assassinato direto" e às doenças, levaram à diminuição da população no México, Todorov (I99I: I30) escreve: “Por 'maus-tratos' entendo basicamente as condições de trabalho impostas pelos espanhóis, particularmente nas minas, mas não só nelas. Os conquistadores-colonizadores não têm tempo a perder, devem enriquecer imediatamente; consequentemente, impõem um ritmo de trabalho insuportável, sem nenhuma preocupação com a preservação da saúde e, portanto, da vida, de seus operários; a expectativa de vida média de um mineiro da época é de vinte e cinco anos. Fora das minas, os impostos são tão despropositados que levam ao mesmo resultado. [...] Paralelamente ao aumento da mortalidade, as novas condições de vida também provocam uma diminuição da natalidade. 'Eles não mais se aproximam das esposas, para não engendrar escravos', escreve o mesmo Zumarraga ao rei; e Las Casas explica: 'Assim, marido e mulher não ficavam juntos e nem se viam durante oito ou dez meses, ou um ano; e quando, ao cabo desse tempo, se encontravam, estavam tão cansados e abatidos pela fome, tão prostrados e enfraquecidos, tanto uns quanto as outras, que pouco se preocupavam em manter comunicações maritais".

I9 Analisei o "estilhaçamento do espelho mágico", em registro benjaminiano, em outros ensaios (ver Dawsey, 2005; 2009).

20 "These experiences that erupt from or disrupt routinized, repetitive behavior begin with shocks of pain or pleasure. Such shocks are evocative: they summon up precedents and likenesses from the conscious or unconscious past for the unusual has its traditions as well as the usual. 
Then the emotions of past experiences color the images and outlines revived by present shock".

2I Benjamin traduziu a obra de Proust, Em busca do tempo perdido.

22 Turner (I986: 43) escreve: "Mas o ritual e a sua progênie, notadamente as artes performativas, derivam do cerne subjuntivo, liminar, reflexivo e exploratório do drama social, onde as estruturas da experiência em grupo (Erlebnis) são replicadas, desmembradas, re-memoradas, refabricadas, e, de forma muda ou vocal, significadas - até mesmo quando, como acontece frequentemente em culturas declinantes, 'o significado é que não há significado'" (tradução e ênfases minhas). A seguir, a versão em inglês: "But ritual and its progeny, notably the performance arts, derive from the subjunctive, liminal, reflexive, exploratory heart of social drama, where the structures of group experience (Erlebnis) are replicated, dismembered, re-membered, refashioned, and mutely or vocally made meaningful - even when, as is so often the case in declining cultures, 'the meaning is that there is no meaning'" (ênfases minhas).

23 "Dismembering may be a prelude to re-membering".

24 "I would go further than Dilthey and see many acts as expressing and fulfilling unconscious purposes and goals".

25 Turner (I974C: IIO; 2008c: I02) escreve: "Um processo primário não se desenvolve a partir de um modelo cognitivo, consciente; ele surge da experiência cumulativa de povos cujas necessidades materiais e espirituais mais profundas há muito tempo não podem ser legitimamente expressadas por causa de uma elite controladora do poder que opera de uma forma análoga à da 'censura' de Freud nos sistemas psicológicos. De fato, em certas situações revolucionárias, pode existir uma relação empírica entre a deposição de uma autoridade política no plano social e a liberação de controles repressivos no plano psicológico". ["A primary process does not develop from a cognitive, conscious model; it erupts from the cumulative experience of whole peoples whose deepest material and spiritual needs and wants have for long been denied any legitimate expression by power-holding elites who operate in a manner analogous to that of Freud's 'censorship' in 
psychological sustems. Indeed there may well be an empirical relationship in certain revolutionary situations between the overthrow of a political authority at the social level and liberation from repressive controls at the psychological level".]

260 termo criollo, como visto anteriormente, se refere a descendentes de espanhóis nascidos nas Américas (ver Turner, I974C: IOI; 2008c: 94). O termo gachupin, que quer dizer "espora", se refere aos espanhóis (ver Turner, I974C: 107; 2008c: 100).

27 Bernardino de Sahagun (I999) discute as diferentes facetas de Tonantzin. Referindo-se a Cihuacóatl como a deusa principal dos mexicas, ele afirma em duas ocasiões que ela era conhecida como Tonantzin. Ver González \& González (2008: 59).

28 "I would suggest that what have been regarded as the "serious" genres of symbolic action - ritual, myth, tragedy, and comedy (at their "birth") - are deeply implicated in the cyclical repetitive views of social process, while those genres which have flourished since the Industrial Revolution (the modern arts and sciences), though less serious in the eyes of the commonality (pure research, entertainment, interests of the elite), have had greater potential for changing the ways men relate to one another and the content of their relationships. Their influence has been more insidious. Because they are outside the arenas of direct industrial production, because they constitute the "liminoid" analogues of liminal processes and phenomena in tribal and early agrarian societies, their very outsiderhood disengages them from direct functional action on the minds and behavior of a society's members. To be either their agents or their audiences is an optional activity - the absence of obligation or constraint from external norms imparts to them a pleasureable quality which enables them all the more readily to be absorbed by individual consciousnesses. Pleasure thus becomes a serious matter in the context of innovative change".

29 "In this book I have not taken up this point, but my concern with complex societies in change (twelfth- 
century England, nineteenth-century Mexico, medieval India, medieval and modern Europe and Asia as settings for pilgrimage processes) points toward this formulation".

30 Benjamin (1985: 23) comenta: "Nem sempre o surrealismo esteve à altura dessa iluminação profana, e à sua própria altura".

3I Turner (I982C: 4I) diz: "As fases liminares da sociedade tribal invertem mas não subvertem, geralmente, o status quo, a forma estrutural da sociedade [...]. Mas gêneros supostamente de 'entretenimento' da sociedade industrial frequentemente são subversivos [...]" (tradução minha). ["The liminal phases of tribal society invert but do not usually subvert the status quo, the structural form of society [...]. But supposedly 'entertainment' genres of industrial society are often subversive [...]".]

32 Em outro ensaio, de modo semelhante, discuti o rito de passagem de Nossa Senhora Aparecida, que também se torna "mulher perigosa" (ver Dawsey, 2006).

33 Benjamin (I985g: 230) escreve: "A consciência de fazer explodir o continuum da história é própria às classes revolucionárias no momento da ação".

$34 \mathrm{Em}$ The ritual process, Turner (I977a: 52) menciona diferentes propriedades dos símbolos, entre quais a polarização do significado. A noção de montagem, me parece, propicia uma análise dessa polarização.

35 "Our Lady of Guadalupe had spatial continuity with the Aztec mother of the gods, Tonantzin. Her cult began only fifteen years after the Aztec Lady's cult had been forcibly discontinued by the Conquest. Moreover, according to the tale known over all Mexico by I8Io, the Queen of Heaven had visited with a simple Indian catechumen, Juan Diego, not with a Spaniard, still less with a Spanish religious" (Turner I974C: I5I-I52).

36 Benjamin (I993f: 223) escreve: "O cronista que narra os acontecimentos, sem distinguir entre os grandes e os pequenos, leva em conta a verdade de que nada do que um dia aconteceu pode ser considerado perdido para a história. Sem dúvida, somente a humanidade redimida poderá apropriar-se totalmente do seu passado. Isso quer dizer: somente para a humanidade redimida o passado é citável, 
em cada um dos seus momentos. Cada momento vivido transforma-se numa citation à l'ordre du jour - e esse dia é justamente o do juízo final". Dilthey, Turner e Benjamin compartilham a suspeita de que o sentido só pode surgir com a morte. Turner (I987d:97) escreve: "Portanto, o sentido da vida de um homem, e de cada momento dele, se manifesta aos outros apenas quando essa vida termina. O sentido dos processos históricos [...] não é e não será conhecido até que eles cheguem ao fim, talvez até que a própria história chegue ao fim, se um fim houver" (tradução minha). ["Thus, the meaning of a man's life, and of each moment in it, becomes manifest to others only when his life is ended. The meaning of historical processes [...] is not and will not be known until their termination, perhaps not until the end of history itself, if such an end there will be".] De uma perspectiva messiânica (benjaminiana) da história, talvez a crítica de Turner (I974d: Ir8; 2008d: I Io) à figura de Hidalgo - "por ter apostado todas as suas fichas nos índios e desistido da posição intermediária dos criollos, a liminaridade criativa que talvez fosse a fonte da sua anterior liderança profética e carismática [...]" - seja precoce. Chama a atenção o inacabamento das histórias: cem anos após a morte de Hidalgo, a sua imagem ressurge no movimento sísmico da Revolução Mexicana (Turner I974d: II3; 2008d: I05). 


\section{REFERÊNCIAS BIBLIOGRÁFICAS}

Barthes, Roland. (1984). A câmara clara. Trad. J. C. Guimarães. Rio de Janeiro: Nova Fronteira.

Benjamin, Walter. (2006). Passagens. Organizado por Willi Bolle. Belo Horizonte/São Paulo: Ed. UFMG/Imprensa Oficial do Estado de São Paulo.

Benjamin, Walter. (I999). The arcades project. Trad. por Howard Eiland e Kevin McLaughlin. Cambridge, MA/Londres: Belknap Press of Harvard University.

Benjamin, Walter. (I995). Sobre alguns temas em Baudelaire. In: Obras escolhidas III: Charles Baudelaire - um lírico no auge do capitalismo. São Paulo: Brasiliense, p. I03-I50.

Benjamin, Walter. (I993a). Rua de mão única. In: Obras escolhidas II: rua de mão única. São Paulo: Brasiliense, p. 9-70. Benjamin, Walter. (I993b). Infância em Berlim por volta de I90o. In: Obras escolhidas II: rua de mão única. São Paulo: Brasiliense, p. 7I-I42.

Benjamin, Walter. (I993C). O conceito de crítica de arte no Romantismo Alemão. São Paulo: Iluminuras/Edusp.

Benjamin, Walter. (I985a). O surrealismo: o último instantâneo da inteligência europeia. In: Obras escolhidas I: magia e técnica, arte e política. São Paulo: Brasiliense, p. 2I-35.

Benjamin, Walter. (1985b). A imagem de Proust. In: Obras escolhidas I: magia e técnica, arte e política. São Paulo: Brasiliense, p. 36-49.

Benjamin, Walter. (1985C). Experiência e pobreza. In: Obras escolhidas I: magia e técnica, arte e política. São Paulo: Brasiliense, p. II4-II9.

Benjamin, Walter. (1985d). Franz Kafka: a propósito do décimo aniversário de sua morte. In: Obras escolhidas I: magia e técnica, arte e política. São Paulo: Brasiliense, p. I37-I64. Benjamin, Walter. (I985e). A obra de arte na era de sua reprodutibilidade técnica. In: Obras escolhidas I: magia e técnica, arte e política. São Paulo: Brasiliense, p. I65-I96.

Benjamin, Walter. (I985f). O narrador: considerações sobre a obra de Nikolai Leskov. In: Obras escolhidas I: magia e técnica, arte e política. São Paulo: Brasiliense, p. I97-22I. 
Benjamin, Walter. (1985g). Sobre o conceito da história. In: Obras escolhidas I: magia e técnica, arte e política. São Paulo: Brasiliense, p. 222-234.

Bolle, Willi. (1994). A fisiognomia da metrópole moderna: representação da história de Walter Benjamin. São Paulo: Edusp. Dawsey, John C. (2009). Por uma antropologia benjaminiana: repensando paradigmas do teatro dramático. Mana, I5/2, p. 349-376.

Dawsey, John C. (2006). Joana Dark e a mulher lobisomem: o rito de passagem de Nossa Senhora. Religião \& Sociedade, 26/2, p. I03-II9.

Dawsey, John C. (2005). Victor Turner e antropologia da experiência. Cadernos de Campo, 13, p. 163-176.

Dilthey, Wilhelm. (2010 [I9I4]). Selected writings. Organizado por Hans Peter Rickman. Cambridge: Cambridge University Press.

Dilthey, Wilhelm. (2006). A construção do mundo histórico nas ciências humanas. São Paulo: Ed. Unesp.

Eisenstein, Sergei. (1990). A forma do filme. Rio de Janeiro: Zahar. Gagnebin, Jeanne Marie. (1994). História e narração em W. Benjamin. São Paulo: Perspectiva/FAPESP/Ed. Unicamp.

Gagnebin, Jeanne Marie. (1985). Prefácio. In: Benjamin, Walter. Obras escolhidas I: magia e técnica, arte e política. São Paulo: Brasiliense, p. 7-20.

Gonzáles, Ondina E. \& Gonzáles, Justo L. (2008). Christianity in Latin America: a history. Cambridge: Cambridge University Press.

Makkreel, Rudolf A. (1975). Dilthey: philosopher of the human studies. Princeton, NJ: Princeton University Press.

Ricard, Robert. (1966). The spiritual conquest of Mexico. Berkeley: University of California Press.

Sahagun, Bernardino de. (1999). Historia general de las cosas de Nueva España, I540-I585. México: Editorial Porrúa. Tradução inglesa: A history of ancient Mexico. Nashville: Fisk University Press, 1932.

Schechner, Richard. (I98I). Restoration of behavior. In: Between theater and anthropology. Philadelphia: University of Pennsylvania Press, p. 35-116. 
Taussig, Michael. (1993). Xamanismo, colonialismo e o homem selvagem: um estudo sobre o terror e a cura. São Paulo/Rio de Janeiro: Paz e Terra.

Todorov, Tzevetan. (I99I). A conquista da América: a questão do outro. 3. ed. São Paulo: Martins Fontes.

Turner, Victor. (2008a) Dramas, campos e metáforas: ação simbólica na sociedade humana. Niterói: EdUFF.

Turner, Victor. (2008b). Apresentação. In: Dramas, campos e metáforas: ação simbólica na sociedade humana. Niterói: EdUFF, p. II-I7.

Turner, Victor. (2008c). Paradigmas religiosos e ação política: Thomas Becket no Concílio de Northampton. In: Dramas, campos e metáforas: ação simbólica na sociedade humana. Niterói: EdUFF, p. 55-90.

Turner, Victor. (2008d.) Hidalgo: a história enquanto drama social. In: Dramas, campos e metáforas: ação simbólica na sociedade humana. Niterói: EdUFF, p. 9I-I44.

Turner, Victor. (2008e). Peregrinações como processos sociais. In: Dramas, campos e metáforas: ação simbólica na sociedade humana. Niterói: EdUFF, p. I55-2I4.

Turner, Victor. (2005 [1986]). Dewey, Dilthey e drama: um ensaio em antropologia da experiência. Cadernos de Campo, I4/I3, p. I77-I86.

Turner, Victor. (2005 [1967]). Floresta dos símbolos: aspectos do ritual Ndembu. Niterói: EdUFF.

Turner, Victor. (I996 [I957]). Schism and continuity in an African society: a study of Ndembu village life. Oxford/Washington D.C.: Berg.

Turner, Victor. (1989 [1967]). The forest of symbols: aspects of Ndembu ritual. Ithaca/Londres: Cornell University Press. Turner, Victor. (I987a). The anthropology of performance. Nova York: PAJ Publications.

Turner, Victor. (1987b). Images and reflections: ritual, drama, carnival, film, and spectacle in cultural performance. In: The anthropology of performance. Nova York: PAJ Publications, p. 2I-32.

Turner, Victor. (I987c). Social dramas in Braziliam Umbanda: the dialectics of meaning. In: The anthropology of performance. Nova York: PAJ Publications, p. 33-7I. 
Turner, Victor. (I987d). The anthropology of performance. In: The anthropology of performance. Nova York: PAJ Publications, p. 72-98.

Turner, Victor. (1985). On the edge of the bush: anthropology as experience. Tucson, Arizona: The University of Arizona Press.

Turner, Victor (org.). (1982). Celebration: studies in festivity and ritual. Washington, D. C.: Smithsonian Institution Press. Turner, Victor. (1982a). From ritual to theatre: the human seriousness of play. Nova York: PAJ Publications.

Turner, Victor. (1982b). Introduction. In: From ritual to theatre: the human seriousness of play. Nova York: PAJ Publications, p. 7-I9.

Turner, Victor. (I982C). Liminal to liminoid, in play, flow, ritual: an essay in comparative symbology. In: From ritual to theatre: the human seriousness of play. Nova York: PAJ Publications, p. 20-60.

Turner, Victor. (I982d). Social dramas and stories about them. In: From ritual to theatre: the human seriousness of play. Nova York: PAJ Publications, p. 6I-88.

Turner, Victor. (I982e). Dramatic ritual/ritual drama: performative and reflexive anthropology. In: From ritual to theatre: the human seriousness of play. Nova York: PAJ Publications, p. 89-IoI.

Turner, Victor. (1982f). Acting in everyday life and everyday life in acting. In: From ritual to theatre: the human seriousness of play. Nova York: PAJ Publications, p. I02-I23. Turner, Victor. (I977a [1969]). The ritual process: structure and anti-structure. Ithaca, NY: Cornell University Press.

Turner, Victor. (1977b [1969]). Liminality and communitas. In: The ritual process: structure and anti-structure. Ithaca, NY: Cornell University Press, p. 94-I30.

Turner, Victor. (1974a). Dramas, fields, and metaphors: symbolic action in human society. Ithaca/Londres: Cornell University Press.

Turner, Victor. (1974b). Preface. In: Dramas, fields, and metaphors: symbolic action in human society. Ithaca/Londres: Cornell University Press, p. I3-I9.

Turner, Victor. (I974C). Religious paradigms and political action: Thomas Becket at the Council of Northampton. 
In: Dramas, fields, and metaphors: symbolic action in human society. Ithaca/Londres: Cornell University Press, p. 60-97. Turner, Victor. (I974d). Hidalgo: history as social drama. In: Dramas, fields, and metaphors: symbolic action in human society. Ithaca/Londres: Cornell University Press, p. 98-I55 Turner, Victor. (1974e). Pilgrimages as social processes. In: Dramas, fields, and metaphors: symbolic action in human society. Ithaca/Londres: Cornell University Press, p. 166-230.

Turner, Victor. (1968). The drums of affliction: a study of religious processes among the Ndembu of Zambia. Oxford: Oxford University Press.

Turner, Victor W. \& Bruner, Edward (orgs.). (I986). The anthropology of experience. Urbana/Chicago: The University of Illinois Press.

Turner, Victor \& Turner, Edith. (1978). Image and pilgrimage in Christian culture. Nova York: Columbia University Press. 
410

\section{TONANTZIN: VICTOR TURNER, WALTER BENJAMIN \\ E ANTROPOLOGIA DA EXPERIÊNCIA}

Resumo

A partir dos escritos de Victor Turner sobre antropologia da experiência e da performance, revisitamos o seu ensaio sobre Hidalgo e a Revolução Mexicana de Independência. Nas margens interiores dessa antropologia encontramos algumas das afinidades entre Turner e Walter Benjamin. Três delas se evidenciam: I) ao realizarem uma arqueologia da experiência, Turner encontra a experiência do liminar, e Benjamin a grande tradição narrativa; 2) ao discutirem transformações que acompanham o capitalismo industrial, Turner fala de um sparagmos, ou desmembramento das formas de ação simbólica; Benjamin da ruína da experiência e do estilhaçamento da tradição; e 3) na busca por formas de reconstituir uma experiência, as atenções de Turner se dirigem às formas liminóides de ação simbólica, e as de Benjamin às novas formas narrativas. Emergem questões. No fundo de cada uma delas, lampeja a imagem de Tonantzin. E a força de alguns dos elementos mais surpreendentes do pensamento de Turner.

\section{TONANTZIN: VICTOR TURNER, WALTER BENJAMIN} AND ANTHROPOLOGY OF EXPERIENCE of his writings on the anthropology of experience and performance. On the internal margins of this anthropology, affinities between Turner and Walter Benjamin are found, three of which are particularly evident: I) while carrying out an archaeology of experience, Turner discovers liminal experience, and Benjamin, the great narrative tradition; 2) in their discussions of transformations which accompany industrial capitalism, Turner speaks of the sparagmos, or dismemberment of forms of symbolic action; and Benjamin, of the ruins of experience and the shattering of tradition; and 3 ) in search of ways to reconstitute meaningful experience, Turner's attentions are directed toward liminoid forms of symbolic action; and Benjamin's, toward new narrative forms. As the image of Tonantzin flashes up, questions emerge, bringing to the surface some of the more surprising elements of Turner's thought.
Palavras-chave

Victor Turner; Walter Benjamin; Tonantzin; Experiência; Performance.
Keywords

Victor Turner; Walter Benjamin; Tonantzin; Experience; Performance. 